\title{
Effects of dietary fat source, breed and vitamin E level on lipid oxidation of sheep muscles
}

\section{Gülcan Demirel}

Research Article

Volume: 3, Issue: 1

April 2019

Pages: $1-5$

\section{Article History}

Received: 28.10.2018

Accepted: 31.12.2018

Available online:

03.01.2019
Istanbul University-Cerrahpasa, Veterinary Faculty, Department of Animal Nutrition and Nutritional Diseases, İstanbul/Turkey. ORCID: 000-0002-6864-5134

\begin{abstract}
The effects of diet and levels of dietary vitamin $E$ on lipid oxidation were assessed in lambs in this study. Groups of Suffolk x Lleyn and Scottish Blackface male lambs were fed dietary lipid supplements containing either Megalac (C16:0), or one of two sources of $n$ 3 PUFA: linseed which has a high content of $\mathrm{C} 18: 3 \mathrm{n}-3$, which had been treated with formaldehyde to aid rumen bypass and a mixture of formaldehyde treated linseed plus fish oil to provide EPA and DHA. The diets were based on dried grass had similar levels of fat $(60 \mathrm{~g} / \mathrm{kg} \mathrm{DM})$. Vitamin E was included as $\alpha$-tocopherol acetate at 100 and $500 \mathrm{mg} / \mathrm{kg}$, for the low and high vitamin $\mathrm{E}$ diets, respectively. The six dietary treatments were: Megalac with low vitamin E, (ML); Megalac with high vitamin E, $(\mathrm{MH})$; Protected linseed with low vitamin E, (LL); Protected linseed with high vitamin E, (LH); Protected linseed plus fish oil (linfish) with low vitamin E, (LFL); Protected linseed plus fish oil mixture (linfish) with high vitamin E, (LFH). At approximately half of the mature live weight for each breed, animals were slaughtered. This was on average $46 \mathrm{~kg}$ for the Suffolk and 36 $\mathrm{kg}$ for the Scottish Blackface. The meat from supplemented animals increased susceptibility to lipid oxidation in high PUFA in meat resulted from poor deposition of dietary vitamin E supplements.
\end{abstract}

Keywords: fatty acids, vitamin E, oxidation, meat, shelf life

DOI: $10.30704 /$ http-www-jivs-net.489172

To cite this article: Demirel G (2019). Effects of dietary fat source, breed and vitamin E level on lipid oxidation of sheep muscles. Journal of Istanbul Veterinary Sciences. 3(1), 1-5, Abbreviated Title: J Ist Vet Sci

\section{Introduction}

The nutritive quality of ruminant meat and its acceptability by consumers would be greatly enhanced if the proportion of unsaturated fatty acids were high and meat were stable to oxidation. Dietary polyunsaturated fatty acids (PUFA) increase membrane unsaturation, as demonstrated in ruminants fed protected fats and consequently increases the susceptibility of meat to oxidation (Wood and Enser, 1997). In addition to the known roles of vitamin $\mathrm{E}$ as a nutrient serving in metabolism and reproduction, its role in product quality has been recognised. The role of supranutritional dietary levels of vitamin $E$ for ruminants to maintain fresh beef colour and to elevate milk tocopherol which reduces lipid oxidation and resulting undesirable milk flavours, has been demonstrated (Arnold et al., 1993; Chauhan et al., 2014).

Wulf et al. (1995) reported that feeding sheep 500 $\mathrm{mg}$ a-tocopherol per day improved lipid stability and colour shelf life for up to four days, when the tissue levels of vitamin $\mathrm{E}$ were in excess of $5.5 \mathrm{mg} / \mathrm{kg}$.

Journal home page: www.jivs.net http://dergipark.gov.tr/http-www-jivs-net 
However, one of the most important factors which alter the effectiveness of vitamin $E$ is the dietary intake of PUFA. Consumption of $n-3$ fatty acids reduces vitamin $E$ concentrations in the blood and tissues more than does n-6 PUFA (Meydani et al., 1987; Raederstorff et al., 2015).

The aim of the study was to examine the effects of supplementation of diets with n-3 PUFA, two levels of vitamin $\mathrm{E}$ and breed on muscle vitamin $\mathrm{E}$ content, lipid oxidation.

\section{Materials and methods}

48 Suffolk $x$ Lleyn and 48 Scottish Blackface male lambs with initial live weights of 24 and $18( \pm 0.3) \mathrm{kg}$, respectively, were used in this study. All diets were based on dry grass and formulated to be iso-energetic and iso-nitrogenic and to provide a similar fat level (60 $\mathrm{g} / \mathrm{kg}$ ) from different fat sources (Megalac, formaldehyde treated linseed and linfish). The control diet contained Megalac which is high in palmitic acid (C16:0), a saturated fatty acid. The second diet, contained formaldehyde treated whole linseed which is high in $\alpha$-linolenic acid and the third diet contained a mixture of equal quantities of linseed and fish oil which supplied performed long chain n-3 PUFA, EPA and DHA. Vitamin E was included as a-tocopherol acetate (Roche Products Limited) at 100 and $500 \mathrm{mg} /$ $\mathrm{kg}$, for the low and high vitamin $\mathrm{E}$ diets, respectively. The six dietary treatments were: Megalac with low vitamin $\mathrm{E},(\mathrm{ML})$; Megalac with high vitamin $\mathrm{E},(\mathrm{MH})$; Protected linseed with low vitamin E, (LL); Protected linseed with high vitamin E, (LH); Protected linseed plus fish oil with low vitamin E, (LFL); Protected linseed plus fish oil mixture with high vitamin $E$, (LFH). All the performance data and feed analysis procedures were published before (Demirel et al., 2004).

Lambs were individually housed in raised floor pens and gradually adapted to a mixed diet containing equal quantities on a weight basis of the three diets. After two weeks on the adaptation diet, all lambs were offered their respective dietary treatments. Feed was offered ad libitum. At approximately half of the mature live weight for each breed, animals were slaughtered. This was on average $46 \mathrm{~kg}$ for the Suffolk and $36 \mathrm{~kg}$ for the Scottish Blackface. From twelve hours before slaughter animals had access to water but not to feed to minimise contamination during slaughter. After slaughter, carcasses were chilled at $1^{\circ} \mathrm{C}$ for 24 hours. Semimembranosus (SM) and Semitendinosus (ST) were cut out and vacuum packed and aged for 6 or 10 days at $1^{\circ} \mathrm{C}$. After 6 or 10 day of ageing, the leg steaks were repackaged in overwrapped (OW) oxygen permeable film and 2 packs were then overpacked in a modified atmosphere (MAP) $\left(75 \% \mathrm{O}_{2}, 25 \% \mathrm{CO}_{2}\right)$. Samples were displayed under simulated retail conditions at 1000 lux illumination and $4 \pm 1^{\circ} \mathrm{C}$ for 5 days. On the last day of display SM and ST muscles were cut out and lipid oxidation determined as thiobarbituric reactivity substances (TBARS) (Vyncke, 1975).

Table 1. Diet composition

\begin{tabular}{lcccccc}
\hline Fat source & \multicolumn{2}{c}{ Megalac } & \multicolumn{2}{c}{ Linseed } & \multicolumn{2}{c}{ Linfish } \\
Vitamin E Level & Low & High & Low & High & Low & High \\
\hline Ingredients (g per kg) & & & & & & \\
\cline { 1 - 5 } Dried grass & 759 & 759 & 739 & 739 & 754 & 754 \\
MSBP & 105 & 105 & 105 & 105 & 105 & 105 \\
Megalac & 35 & 35 & - & - & - & \\
Fish oil & - & - & - & - & 15 & 15 \\
Whole linseed & - & - & 85 & 85 & 42 & 42 \\
Soya bean meal & 46 & 46 & 16 & 16 & 29 & 29 \\
Molasses & 25 & 25 & 25 & 25 & 25 & 25 \\
Mineral and vitamin premix & 20 & 20 & 20 & 20 & 20 & 20 \\
Ammonium chloride & 5 & 5 & 5 & 5 & 5 & 5 \\
Salt & 5 & 5 & 5 & 5 & 5 & 5 \\
Vitamin E mg/kg & 100 & 500 & 100 & 500 & 100 & 500 \\
\hline
\end{tabular}

Key: MSBP Sugar beet pulp with molasses 


\section{Results and Discussion}

Lipid oxidation after 6 and 10 days of ageing and 5 days of display was evaluated with the TBA-test. Statistical analysis showed that there is no significant difference between 6 and 10 days ageing of the muscles. Mean values in m.semitendinosus (ST) were 4.4 and 4.9 and in m.semimembranosus (SM) 5.5 and $5.1 \mathrm{mg} \mathrm{MDA} / \mathrm{kg}$ muscle (sed=0.30, NS) for 6 and 10 days ageing, respectively. Effects of diet, breed and vitamin $E$ on TBA values and significance of the main effects and interaction are in Table 2.

\section{(a) semitendinosus muscle}

As a result of low vitamin $E$ levels in muscle, TBA values was higher than acceptable value of 0.5-1.0 (Gray and Pearson, 1987) in muscles from all groups after 5 day simulated display. There was an increase in TBA numbers from Megalac to linseed and linfish. Mean values were 2.66, 4.81 and $6.56 \mathrm{mg} \mathrm{MDA} \mathrm{/} \mathrm{kg}$ muscle (sed $=0.38, p<0.001$, Table 2 ) for muscles from Megalac, linseed and linfish fed lambs. There were no significant breed and vitamin E effects on TBA values. But, Scottish Blackface lambs showed a response to higher vitamin $E$ by having lower TBA values after fed one of the diets with high levels of vitamin $\mathrm{E}(\mathrm{MH}, \mathrm{LH}$ or LFH). Mean values were 5.3 and $3.92 \mathrm{mg} \mathrm{MDA} \mathrm{/} \mathrm{kg}$ muscle (sed $=0.45, p<0.01$, Table 2 ) for low and high vitamin $\mathrm{E}$ diets. The values were for Suffolk lambs 4.81 and $4.59 \mathrm{mg} \mathrm{MDA} / \mathrm{kg}$ muscle (sed=0.45, NS).

\section{(b) semimembranosus muscle}

Similar to the ST muscle, TBA values in the SM muscle were higher than acceptable values. Statistical analysis showed that the SM muscle had significantly higher values than the ST. Mean values were 4.66 vs. $5.28 \mathrm{mg} \mathrm{MDA} / \mathrm{kg}$ muscle (sed $=0.21, \mathrm{p}<0.01$ ). The reason of this differences is that semimembranosus is an oxidative muscle, containing more mitochondria and therefore a higher content of long chain PUFA compared to the semitendinosus which is a more glycolytic muscle. Also oxidative muscles contain more free fatty acids than glycolytic ones (Sklan et al.,1983). The free fatty acids contain a large amount of long chain PUFA which come unambiguously from phospholipids (Zierath and Hawley, 2004). Therefore, the greater content of $\alpha$-tocopherol in oxidative muscle than in white muscle may be necessary to provide protection for the increasing lipid unsaturation in the dark (oxidative) muscle. There was also a significant effect of diet on TBA values with mean values $3.96,5.54$ and $6.37 \mathrm{mg} \mathrm{MDA} / \mathrm{kg}$ muscle (sed $=0.35, p<0.001$, Table 2) for Megalac, linseed and linfish fed lamb muscles. Similarly to the ST muscle, no significant effects of breed and vitamin $\mathrm{E}$ on lipid oxidation were observed. As an interaction effect, Scottish Blackface lambs also showed, in SM muscle, much more response to a higher level of vitamin $\mathrm{E}$ and they had lower TBA values than when fed the low level of vitamin E. Mean values 5.77 vs. $4.63 \mathrm{mg} \mathrm{MDA} /$ kg muscle (sed $=0.40, p<0.05$ ).

In Suffolk lambs these values were similar, 5.23 vs. $5.50 \mathrm{mg} \mathrm{MDA} / \mathrm{kg}$ muscle. In SM muscle another interaction effect was observed. In the muscle of linfish fed lambs high vitamin E decreased the lipid oxidation while linseed and Megalac fed lambs did not show a difference. In linfish fed lambs values decreased from 7.08 to $5.7 \mathrm{mg} \mathrm{MDA} / \mathrm{kg}$ muscle (sed= $0.50, p<0.05)$.

Table 2. Effects of dietary fat, breed and vitamin E on lipid oxidation ( $\mathrm{mg} M D A / k g$ muscle) in semitendinosus and semimembranosus muscles of lamb

\begin{tabular}{|c|c|c|c|c|c|c|c|c|c|c|c|c|c|}
\hline & \multicolumn{4}{|c|}{ Megalac } & \multicolumn{4}{|c|}{ Linseed } & \multicolumn{5}{|c|}{ LinFish } \\
\hline & \multirow{2}{*}{\multicolumn{2}{|c|}{$\begin{array}{c}\text { Low } \\
\text { Suffolk Blackface }\end{array}$}} & \multicolumn{2}{|c|}{ High } & \multicolumn{2}{|c|}{ Low } & \multicolumn{2}{|c|}{ High } & \multicolumn{2}{|c|}{ Low } & \multicolumn{3}{|c|}{ High } \\
\hline & & & Suffolk & Blackface & Suffolk & Blackface & Suffolk & Blackface & Suffolk & Blackface & Suffolk & Blackface & SED \\
\hline $\begin{array}{l}\text { MDA, } \\
\mathrm{mg} / \mathrm{kg} \text { (ST) }\end{array}$ & 2.84 & 3.04 & 2.95 & 1.81 & 4.90 & 4.76 & 4.31 & 5.29 & 6.12 & 8.37 & 7.22 & 4.73 & 0.73 \\
\hline $\begin{array}{l}\text { MDA } \\
\mathrm{mg} / \mathrm{kg}(\mathrm{SM})\end{array}$ & 4.95 & 3.43 & 4.77 & 2.70 & 4.79 & 5.77 & 5.04 & 6.55 & 6.01 & 8.28 & 6.71 & 4.70 & 0.71 \\
\hline \multicolumn{14}{|c|}{ Main effects and interactions } \\
\hline & & Fat & Breed & Vitamin E & \multicolumn{2}{|c|}{ Fat $x$ Breed } & \multicolumn{2}{|c|}{ Fat $x$ Vit. E } & \multicolumn{2}{|c|}{ Breed x Vit. E } & \multicolumn{3}{|c|}{ Fat $x$ Breed $x$ Vit. E } \\
\hline $\begin{array}{l}\text { MDA } \\
\mathrm{mg} / \mathrm{kg} \text { (ST) }\end{array}$ & & $* * *$ & ns & ns & \multicolumn{2}{|c|}{$\mathrm{ns}$} & \multicolumn{2}{|c|}{ ns } & \multicolumn{2}{|c|}{$* *$} & \multicolumn{3}{|c|}{$* * *$} \\
\hline $\begin{array}{l}\text { MDA } \\
\mathrm{mg} / \mathrm{kg}(\mathrm{SM})\end{array}$ & & $* * *$ & ns & ns & \multicolumn{2}{|r|}{$* * *$} & \multicolumn{2}{|r|}{$*$} & \multicolumn{2}{|r|}{$*$} & \multicolumn{3}{|c|}{$* *$} \\
\hline
\end{tabular}

ns $=$ not significant, ${ }^{*}=p<0.05,{ }^{* *}=p<0.01,{ }^{* * *}=p<0.001$, MDA: malonaldehyde, $S T:$ m.semitendinosus

$\mathrm{SM}: \mathrm{m}$. semimembranosus 
Many studies have assessed the effects of added dietary fat on oxidative stability of meat. Oxidative rancidity is a major cause of meat deterioration and involves the oxidation of the unsaturated fatty acids, particularly the polyunsaturated fatty acids. Moerck and Ball (1974) showed that fatty acids with three or more double bonds are very susceptible to oxidation during refrigerated storage of meat and that the susceptibility increases with the number of double bonds in the fatty acids. The vitamin $E$ content of muscle foods during storage influences the rate of lipid oxidation and subsequent changes in fatty acid composition. Porcine muscle with the highest concentrations of $\alpha$-tocopherol per gram of fatty acids with three or more double bonds, had the lowest TBA numbers after cooking or three days of storage (Lynch et al., 1999, Yamauchi et al., 1980).

Although fresh forage has the potential to supply large amounts of vitamin $\mathrm{E}$, the amount deposited in the animal may be reduced by the presence of the oxidatively unstable $\alpha$-linolenic acid in the forage (Moloney et al., 2008). Furthermore, the difference in the PUFA composition of the tissues produced by the dietary $\alpha$-linolenic acid from forage compared with mainly linoleic acid from grains also increases the potential for oxidation in meat hence increasing the demand for vitamin $\mathrm{E}$.

In the present study, it seems that dietary n-3 stimulated lipid oxidation was not suppressed even at the high level of vitamin E supplementation because of low tissue levels (Demirel et al.,2004). Thus, the supply of vitamin $E$ may be inadequate and/or the antioxidative function of vitamin $E$ was inefficient in the presence of the highly unsaturated fatty acid. Farwer et al. (1994) and Kubo et al. (1997) observed similar results in rats fed on diets $n-3$ fatty acids. Thus, vitamin E may not protect membranes rich in $n-3$ fatty acids, especially those with five or six double bonds, from lipid oxidation as efficiently as membranes rich in $n-6$ fatty acids, as suggested by Kaasgaard et al. (1992).

In conclusion, supplementation of diet with n-3 enhanced the susceptibility of muscle to lipid oxidation concomitant with higher levels of $n-3$ in muscles despite the poor protection and extensive rumen biohydrogenation. In addition, the amount of vitamin E present was unable to protect membranes of these muscles from lipid oxidation even after ingestion of high levels of vitamin $\mathrm{E}$.

(Ed). Advances in meat research, vol:3. (pp. 221). New York, US: Van Nostrand Reinhold Company.

Kaasgaard, S. G., Holmer, G., Hoy, C. E., Behrens, W. A., \& Beare-Rogers, J. L. (1992). Effect of dietary linseed oil and marine oil on lipid oxidation in monkey liver in vivo and in vitro. Lipids, 27(10),740-745.

Kubo, K., Saito, M., Tadokoro, T., \& Maekawa, A. (1997). Changes in susceptibility of tissues to lipid peroxidation after ingestion of various levels of decosahexaenoic acid and vitamin E. British Journal of Nutrition, 78(4), 655-669.

54, 1525-1536.

Demirel, G., Wachira, A. M., Sinclair, L. A., Wilkinson, R. G., Wood, J. D., \& Enser, M. (2004). Effects of dietary $\mathrm{n}-3$ polyunsaturated fatty acids, breeds and vitamin $\mathrm{E}$ on the fatty acids of lamb muscle, liver and adipose tissue. British Journal of Nutrition, 91(4), 551-565.

Farwer, S. R., Boer, B. C. J. D, Haddeman, E., Kivits, G. A. A., Wiersma, A., \& Danse, B. H. J. C. (1994). The vitamin $E$ nutritional status of rats fed on diets high in fish oil, linseed oil or sunflower seed oil. British Journal of Nutrition, 72(1), 127-145.

Gray, J. I., \& Pearson, A. M. (1987). Restructured Meat and Dairy Products In: A. M. Pearson, T. R. Dutson
Lynch, M. P., Kerry, J. P., Buckley, D. J., Faustman, C., \& Morrissey, P. A. (1999). Effect of dietary vitamin E supplementation on the colour and lipid stability of fresh, frozen and vacuum-packaged beef. Meat Science, 52(1), 95-99.

Moerck, K. E., \& Ball, H. R. (1974). Lipid oxidation in mechanically deboned chicken meat. Journal of Food Science, 39(5), 876-879.

Meydani, S. N., Shapiro, A. C., Meydani, M., MaCauly, J. B., \& Blumberg, J. B. (1987). Effect of age and dietary fat(fish oil, corn oil and coconut oil) on tocopherol status of mice. Lipids, 22(5), 345-350. 
Moloney, A. P, Fievez, V., Martin, B, Nute, G. R., \& Richardson, I. (2008). Biodiversity and animal feed: future challenges for grassland production. Proceedings of the 22nd General Meeting of the European Grassland Federation, Uppsala, Sweden, 912 June.

Raederstorff, D., Wyss, A., Calder, P. C., Weber, P., \& Eggersdorfer, M. (2015). Vitamin E function and requirements in relation to PUFA. British Journal of Nutrition, 114(8), 1113-1122.

Sklan, D., Tenne, Z., \& Budowski, P. (1983). Simultaneous lypolytic and oxidative changes in turkey meat stored at different temperatures. Journal of Science Food and Agriculture, 34(1), 9399.

Vyncke, W. (1975). Evaluation of the direct thiobarbituric acid extraction method for determining oxidative rancidity in Mackerel. Fette, Seifen, Anstrichmittel, 77(6), 289-240.
Wood, J. D., \& Enser, M. (1997). Factors influencing fatty acids in meat and the role of antioxidants in improving meat quality. British Journal of Nutrition 78(Suppl. 1), S49-S60.

Wulf, D. M., Morgan, J. B., Sanders, S. K., Tatum, J. D., Smith, G. C., \& Williams, S. (1995). Effects of dietary supplementation of vitamin $E$ on storage and case life properties of lamb retail cuts. Journal of Animal Science, 73(2), 399-405.

Yamauchi, K., Nagai, Y., \& Ohashi, T. (1980). Quantitative relationship between a-tocopherol and polyunsaturated fatty acids and its connection to development of oxidative rancidity in porcine skeletal muscle. Agricultural and Biological Chemistry, 44(5),1061-1067

Zierath, J. R., \& Hawley, J. A. (2004). Skeletal Muscle Fiber Type: Influence on Contractile and Metabolic Properties. PLoS Biology, 2(10), e337-e348. 